\title{
Estilo conversacional, interculturalidade e língua estrangeira
}

Selma Meireles*

\begin{abstract}
At the same time that language is fundamental for establishing and maintaining social-cultural groups, it is also influenced by them to the extent that a number of social-cultural conventions are unconsciously mirrored in their members' linguistic manifestations. Different expectations regarding conversational style in interactions between speakers from different cultural groups can lead to misunderstandings, conflicts or even to the creation and perpetuation of stereotypes. This paper will present some examples and considerations of conversational style and interculturality in general and about conversational style in German and Brazil in particular.
\end{abstract}

Keywords: Conversational Style; Interculturality; Foreign Language; Intercultural Conflicts.

Zusammenfassung: Obwohl die Sprache einer der Grundsteine bei der Formierung und Aufrechterhaltung soziokultureller Gruppen ist, wird sie auch von eben diesen Gruppen beeinflusst. In den linguistischen Beiträgen der Mitglieder solcher Gruppen spiegeln sich verschiedene soziokulturelle Konventionen unbewusst wider. Unterschiedliche Erwartungen in bezug auf den Konversationsstil bei Interaktionen zwischen Sprechern verschiedener Kulturen können deshalb zu Missverständnissen, Konflikten und sogar zur Bil-

A autora é docente de língua alemã e lingüística no Departamento de Letras Modernas da FFLCH da USP. 
dung bzw. Verstärkung von Stereotypen führen. Ziel dieses Aufsatzes ist es, einige Beispiele und Überlegungen zu Konversationsstil und Interkulturalität im allgemeinen und zum Verhältnis zwischen Deutschen und Brasilianern im besonderen zu präsentieren.

Stichwörter: Konversationsstil; Interkulturalität; Fremdsprachen; Kulturschock.

Resumo: Ao mesmo tempo em que a linguagem é parte fundamental da constituição e manutenção de grupos sócio-culturais, ela também é influenciada por eles, a ponto de espelhar inconscientemente diversas convenções sócio-culturais nas manifestações lingüísticas dos membros de tais grupos. Discrepâncias nas expectativas em relação a estilos conversacionais em interações entre falantes de grupos culturais diferentes podem ocasionar mal-entendidos, conflitos ou mesmo levar à criação e manutenção de estereótipos. Este artigo tem como objetivo apresentar alguns exemplos e considerações a respeito de estilo conversacional e interculturalidade em geral e no que se refere ao estilo conversacional de brasileiros e alemães.

Palavras-chave: Estilo conversacional; interculturalidade; língua estrangeira; conflitos interculturais.

\section{Introdução}

Desde o início dos estudos da sociedade, não há duvidas quanto à interrelação entre cultura e língua. Um grupo cultural é geralmente identificado como compartilhando uma língua (ou linguagens) e muitos estudiosos consideram a linguagem como o principal fator de construção e manutenção da realidade social (cf. FILIP 1998).

Se a linguagem é parte fundamental da constituição de um grupo social, por outro lado também ela é influenciada por ele a ponto de, como afirma MÜLLER-JAQUIER (1998), “todas as diferenças culturais [estarem] 'ocultas' nas manifestações lingüísticas". Q Quando confrontados com diferentes formas ou padrões de expressão lingüística, reconhecemos que estamos

1 As traduções dos trechos citados são de minha autoria. 
diante de grupos sociais ou culturais distintos, sejam eles subgrupos de nossa cultura materna ou característicos de outras culturas.

Entre os diversos padrões de expressão lingüística há um que ainda permanece pouco explorado, mas que apresenta um grande potencial para a pesquisa sócio-lingüística: a relação entre estilo conversacional e interculturalidade.

\section{Estilo conversacional e cultura}

O termo "estilo conversacional" foi popularizado pela norte-americana Deborah Tannen, que realizou vários estudos sobre os padrões comunicativos de pessoas de diferentes sexos e culturas. O estilo conversacional pode ser definido como o conjunto de características de "como dizer alguma coisa". Pode ser típico tanto de um indivíduo como de um grupo ou de uma sociedade.

Normalmente não nos damos conta de como nossa cultura influencia o modo como planejamos e realizamos a nossa comunicação. No entanto, GuMPERz \& CoOK-GuMPERZ (1982: 12) argumentam que:

Embora as condições pragmáticas de tarefas comunicativas sejam comumente aceitas como universais em teoria, a realização dessas tarefas enquanto prática social varia de acordo com a cultura. Esta variação pode ser analisada de diversas perspectivas, as quais naturalmente co-ocorrem na prática:

- Diferentes pressuposições sociais sobre a situação e sobre o comportamento apropriado e as intenções ligadas a ela.

- Diferentes modos de estruturar a informação ou a argumentação em uma conversação.

- Diferentes modos de falar: uso inconsciente de conjuntos diferentes de convenções lingüísticas (escolha de léxico, registro, prosódia, pausas, entoação, idiomatismos) para enfatizar ou sinalizar conexões lógicas e indicar a importância do que está sendo dito em termos de significado geral e atitudes.

Em casos de comunicação entre membros de uma mesma cultura, as diversas possibilidades de combinação dos fatores elencados acima já são co- 
nhecidas dos interlocutores. Estes, por sua vez, baseados em seu conhecimento dos padrões existentes em sua cultura, atribuem-lhes os significados adicionais que aprenderam estarem associados a eles, através de sua socialização e do convívio com os demais membros de seu grupo cultural. Assim, somos capazes de julgar se uma pessoa está ou não agindo adequadamente dentro dos pressupostos sociais que atribuímos a cada situação comunicativa e, através disso, atribuímos-lhe valores como educação, gentileza, hostilidade, habilidade na organização de idéias e na escolha das palavras, grau de auto-estima, expectativa quanto a efeitos perlocutórios etc.

Sempre que iniciamos uma interação lingüística, utilizamos inconscientemente os padrões de estilo conversacional que adquirimos em nossa cultura. No entanto, tais expectativas podem não ser consideradas totalmente válidas quando nos defrontamos com interlocutores de grupos culturais diferentes do nosso (ou daqueles com os quais estamos acostumados a interagir).

Da mesma forma que selecionamos nosso estilo conversacional, nosso interlocutor irá utilizar padrões que não necessariamente coincidem com os nossos, o que pode acarretar grandes problemas de comunicação. Geralmente tais problemas são atribuídos à falta de domínio adequado do código lingüístico no qual está sendo realizada a interação. No entanto, eles surgem mesmo em situações na qual todos os interlocutores dominam relativamente bem o idioma usado na comunicação. Em tais situações, como as dificuldades comunicativas geradas pela discrepância de estilos conversacionais não podem ser atribuídas ao domínio da língua, invariavelmente os interlocutores atribuem tais problemas a características negativas da personalidade do interlocutor e, baseados em diversos encontros semelhantes com outros membros daquela mesma cultura, passam a generalizar tais impressões (desfavoráveis ou favoráveis) em relação a todos os membros daquela cultura. Vejamos agora mais detalhadamente como isso acontece.

\section{Problemas em interações interculturais}

Expressões de diferenças culturais são encontradas em todas as línguas. Podem surgir em diversas categorias gramaticais e semânticas ou mesmo serem expressas em elementos não verbais, sendo apresentadas de formas 
específicas explícitas ou implícitas tanto pelos falantes como pelos ouvintes. Isto resulta em uma fonte em potencial de mal-entendidos mútuos, quando os indicadores ou manifestações lingüísticas não são adequadamente percebidos pelos interlocutores.

O estudo e caracterização de estilos ligados a diferenças culturais não apenas ajuda a identificar possíveis áreas de mal-entendidos, mas também a revelar predisposições dos participantes para julgar aqueles que divergem de seus padrões conversacionais. Como as normas conversacionais são comuns a todos os membros de um grupo, estes julgamentos tendem a se cristalizar em estereótipos culturais. MÜLLER-JAQUiER (1998) faz referência a diferenças no estilo conversacional como fonte de estereótipos e preconceitos entre britânicos e alemães. Em entrevistas realizadas após encontros de negócios com representantes de empresas alemãs, os britânicos consideraram os alemães "agressivos" e "diretos demais" em situações de pedidos. O problema, segundo o identificou MüLLER-JAQUIER, era a quebra de expectativa dos britânicos quanto à freqüência de uso do item lexical 'please' e sua impossibilidade de reconhecer os outros meios de atenuação utilizados pelos alemães (Konjunktiv, entoação). De qualquer modo, os falantes britânicos atribuíram a falta (ou menor freqüência de uso) da palavra please por parte dos alemães ao fato de eles "serem mais rudes".

Tais conclusões derivam do fato de os falantes automaticamente interpretarem diferenças sistemáticas de regras lingüísticas como características psicológicas. Mesmo a mudança da realidade exterior (p.ex. a presença em outro país) ou a aceitação "intelectual" de contra-evidências apresentadas pelo interlocutor não é o bastante para eliminar este fenômeno.

\section{4. Área potenciais de conflitos}

Infelizmente, as áreas potenciais para surgimento de conflitos estendem-se por praticamente todos os níveis lingüísticos, conforme aponta MüLLERJAQUIER (1998). Vejamos alguns exemplos:

a) Diferenças no significado social de itens lexicais. Por exemplo, o simples conceito de uma palavra que parece não oferecer dificuldades, como "domingo", evoca diferentes conotações em diferentes culturas. Enquanto no Brasil o conceito de "domingo" é positivo no que se refe- 
re a um dia sem trabalho, dedicado à religião, mas também a passeios com a família ou à ida ao jogo de futebol, em alguns países da Europa, por exemplo, o conceito de "domingo" pode estar associado ao tédio e à tristeza, pois as lojas não abrem e não há nada para se fazer fora de casa (como mostram os versos da música "Everyday is like Sunday" de Morrisey: "Everyday is like Sunday / Everyday is silent and gray").

b) Diferenças na escolha dos atos de fala e das seqüências de atos de fala. Müller-Jaquier cita o modo "direto e descortês" de os alemães pedirem algo em certas situações, como em: "Ich krieg erstmal ein Bier, aber'n großes!" ("eu quero uma cerveja, mas das grandes!"), o que soa como uma "ordem" para muitos.

Do mesmo modo, a seqüência dos atos de fala em uma interação aponta para diferentes convenções referentes à organização do discurso e leva em conta parâmetros como diferenças de registro, conteúdo apresentado de forma mais ou menos explícita etc. Como um exemplo, estudos que se ocupam de interações entre falantes chineses e alemães (cf., p.ex., GÜNTHNER 1993) apontam para problemas comunicativos porque o padrão conversacional chinês exige que, antes de emitirem uma opinião, os chineses exponham todas as razões que os levaram àquela conclusão, enquanto os alemães têm a expectativa de ouvir as razões apenas após a opinião ter sido expressa. Assim, a interpretação dos alemães é de que os chineses não são capazes de exprimir diretamente sua opinião (ou mesmo que não a têm, já que o ouvinte alemão geralmente interrompe a fala do chinês antes que este possa declará-la). Desse modo, muitos falantes alemães acham que os chineses "não têm personalidade própria" enquanto falantes chineses consideram os alemães altamente arrogantes, sempre expressando suas opiniões "subjetivas".

c) Diferenças na organização da conversação: Diferenças na duração e/ ou seqüência das fases da conversação (por exemplo, na apresentação de uma pessoa ou de um tema, small talk, escolha do momento certo para introdução de exemplos ou piadas etc.) podem dar a impressão de que o interlocutor é por demais ríspido ou leviano. Diferenças no gerenciamento de turnos também dão essa impressão. Por exemplo, falantes franceses parecem aceitar melhor fases em que duas pessoas falam ao mesmo tempo. 
Isto é geralmente interpretado por falantes alemães como sinal de discordância, mas para os franceses é visto como uma forma de apoio ao falante. Em interações entre americanos e alemães, BYRNEs (1986) relata problemas causados não pelo conteúdo, mas por diferenças nas seqüências de tópicos escolhidos e no modo de abordá-los.

d) Temas tratados: Cada cultura tem regras específicas sobre quais temas devem ser abordados com quem, quando, onde e com qual grau de abertura. Por exemplo, Byrnes (1986) ressalta que religião é um tema tabu na América entre pessoas que não se conhecem muito bem, enquanto aparece relativamente cedo em conversas entre alemães. Em conversas entre chineses e alemães, costuma causar desconforto a relativa facilidade com que alemães discutem noções gerais de sexualidade e com que os chineses fazem perguntas diretas a respeito do estado civil e do salário dos alemães.

e) Grau de explicitude: $O$ grau de explicitude está muito ligado à quantidade de palavras e ao tempo que se gasta em cada tópico. Por exemplo, a expressão de discordância por parte de alemães é normalmente sentida como excessivamente direta por brasileiros, que a atribuem à "frieza e objetividade dos alemães". Por outro lado, quando brasileiros relutam em exprimir sua discordância diretamente, os alemães interpretam tal comportamento como uma prova de que brasileiros são "dissimulados" e tendem a exigir uma "resposta franca", o que embaraça ainda mais o brasileiro. Segundo Müller-Jaquier (1998), "quanto mais indiretos forem os enunciados, maior será a tendência de um falante de uma comunidade que preza a expressão direta de suas intenções de fala a tentar resolver o problema meta-comunicativamente, o que fere ainda mais as regras do interlocutor".

f) Fatores paraverbais: diferenças em ritmo, altura da voz, velocidade de fala, entoação, quantidade e duração das pausas são interpretadas de modo diferente em diversas culturas. Por exemplo, em alemão, pausas longas podem ser interpretadas como sinal de insegurança e devem ser evitadas, porque são vistas como constrangedoras. Da mesma forma, o tom de voz de alguns franceses é freqüentemente considerado excessivamente agudo e irritante por muitos alemães, assim como o volume de vOz dos italianos. 
g) Fatores não-verbais: Amplitude e freqüência dos gestos e distância entre os interlocutores são fatores que influenciam muito a comunicação. Por exemplo: enquanto os franceses acham que alemães têm um gestual vagaroso e restrito, que leva ao desinteresse, alemães e ingleses ficam intimidados com a pequena distância que os latinos mantém entre os participantes de uma interação. Isso faz com que o alemão ou inglês procure retomar a distância corporal que ele julga adequada, afastandose do interlocutor latino. Este, por sua vez, não se sente confortável com o afastamento do interlocutor e se aproxima dele, "ameaçando-o", o que leva a uma desagradável "dança".

h) Valores e crenças específicos de cada cultura: Vários estudos apontam para diferenças culturais como individualismo vs. coletivismo (maior valorização do indivíduo ou do grupo): por exemplo, os japoneses prezam muito a harmonia do grupo e não vêem com bons olhos a ostentação de conquistas individuais, ao contrário dos americanos, que prezam a noção de self-made man. Outro exemplo é a maior ou menor tendência de cada cultura a evitar situações não-controladas, por exemplo, planejar minuciosamente o roteiro de uma viagem ou iniciar um passeio mesmo sem saber ao certo o que se vai fazer.

\section{Em busca do estilo conversacional alemão}

Em um artigo de 1986, BYRnes apresenta uma proposta de comparação entre os estilos conversacionais de americanos e alemães. Utilizando os conceitos de polidez negativa e positiva de BRown \& Levinson (que ela denomina respectivamente de "polidez deferencial" (deference politeness), no qual o falante "cede" mais espaço ao interlocutor e "polidez solidária" (solidarity politeness), que enfatiza o grupo em detrimento do indivíduo e procura eliminar ou disfarçar diferenças), propõe que, em comparação com o estilo alemão, o estilo americano é direcionado a estratégias de polidez deferencial, preferindo abordagens mais indiretas dos temas.

Comparado ao alemão, o estilo americano poderia ser caracterizado por pouca sobreposição nas mudanças de turno e pronunciada prontidão para ceder o turno quando tal sobreposição acontece. O tom de voz é geralmente baixo, com menor flutuação entoacional, dando a impressão geral de menos apego e envolvimento aos tópicos tratados e maior preocu- 
pação em criar um clima agradável para os outros. Os tópicos são mais um veículo para estreitamento das relações pessoais do que uma busca da verdade. Quando um tópico está sendo enfocado, os interlocutores tendem a fazer suas contribuições de modo negociável, apresentando sua opinião pessoal cautelosamente, deixando aos demais a escolha sobre aceitá-la ou não. A ambigüidade dessa abordagem evita danos potenciais à harmonia que domina a superfície da conversação.

BYRNES comenta que as raízes para tal comportamento podem estar no processo de socialização dos americanos, que desde a infância praticam uma alta valorização do indivíduo e de sua liberdade. Ao mesmo tempo, essa liberdade só é possível quando os demais membros do grupo também a aceitam, o que leva a evitar conflitos potencialmente desestabilizadores das relações pessoais. Durante a sua escolarização, os alunos americanos são treinados a produzirem textos orais e escritos levando fortemente em conta a atenção e as vontades / necessidades da audiência. O ônus de criar e manter uma comunicação bem sucedida repousa sobre o falante, entre os americanos (que são incentivados a construírem suas estratégias respeitando a individualidade do outro), e sobre os ouvintes, entre os alemães (que, segundo afirma BYRNES (1986: 200), "devem interpretar o sentido correto das intenções 'less than transparent' dos falantes alemães").

Por outro lado, para o estilo alemão, BYRNES ressalta que o mais importante não são as estratégias de polidez, mas sim uma maior ênfase na função informativa da linguagem do que na função social / interacional. Há uma maior preocupação com os fatos e valores de verdade (truth-value), o que justifica (ou exige) o uso de discordância aberta ou mesmo confrontação. BYRNES afirma que, na realidade, esses procedimentos são altamente valorizados e tornaram-se quase ritualísticos por serem vistos como procedimentos que levam ao estabelecimento da verdade. Assim, o falante pode apresentar suas contribuições com maior complexidade e usando referências a ideologias que justificam e legitimam suas posições. Enquanto isso diminui o espaço para a discussão consensual, também empresta maior profundidade à discussão e às conclusões atingidas. Talvez para os alemães isso tenha se transformado também em um fator de estabelecimento e manutenção de relações pessoais. 
Em virtude dessa preocupação, são usadas estratégias mais diretas e os participantes apresentam um nível maior de envolvimento com o tópico em questão. A fala é marcada por sobreposições, variação no volume, pausas mais curtas ou inexistentes nas mudanças de turno, interlocutores terminando as falas dos demais e participação altamente emocional. BYRNES (1986: 202) afirma que "freqüentemente o indivíduo coloca o seu ego em risco ao defender posições cuja validade só pode ser provada se as posições dos demais forem contestadas".

Contudo, isso não significa que falantes alemães sempre sejam diretos e "agressivos". Um estudo sobre as estratégias de trabalho da Face usada em diferentes tipos de dissensão (MEIRELEs 2005) mostrou que também entre os alemães as situações que são potencialmente mais delicadas em termos de interação pessoal exigem estratégias menos diretas. No corpus examinado, nota-se que a expressão direta da discordância apenas é o padrão em situações de dissensão referente a partes da proposição, ou seja, ocasiões nos quais o falante "corrige" o interlocutor sem invalidar totalmente sua proposta. Por outro lado, em situações nas quais a dissensão pode ser vista como uma crítica (discordância do todo da proposição apresentada pelo interlocutor) ou uma ameaça ao bom andamento da interação, cresce a utilização de estratégias off record, ou seja, procedimentos que procuram realizar a dissensão de modo indireto, sem que o falante possa ser responsabilizado claramente por ela.

\section{Estilo conversacional centrado no falante / ouvinte}

Voltando ao tema de formação de estereótipos e da impossibilidade de perceber problemas no estilo conversacional, BYRNES constatou, após realizar entrevistas com estudantes de ambas as nacionalidades, que alemães vêem os americanos como interlocutores superficiais, desinformados, irresponsáveis e desinteressados, que sempre tentam parecer amigáveis, mas cujo conhecimento e capacidade de discussão de temas como sociedade, religião, política, filosofia etc. é muito reduzido, e por essa razão não querem ou não são capazes de formar e defender uma opinião. Por sua vez, os americanos vêem os alemães como espertos, mas dogmáticos, mesmo teimosos, muito envolvidos e engajados em suas causas, que obrigatoriamen- 
te debatem um assunto que pode ter múltiplos matizes ou mesmo nenhuma resposta definida em termos de dicotomias de certo / errado, colocando os interlocutores na defensiva e mesmo humilhando-os em frente ao grupo, ao mesmo tempo em que se autovalorizam de forma extrema. Novamente, vemos como a incompatibilidades de diferentes padrões comunicativos é geralmente atribuída a características psicológicas.

As considerações apresentadas no artigo de BYRNES encontram eco em um estudo de Kohnen (1987). Analisando discussões entre falantes alemães, ingleses e irlandeses, KOHNEN propõe a existência de dois "estilos" de argumentação: o "centrado no falante" e o "centrado no ouvinte".

O estilo centrado no falante procura ressaltar os pontos de vista do falante como válidos e incontestáveis, apoiando-se em dados concretos, citações ou argumentos objetivos. Cada participante procura sair-se melhor na discussão e provar o seu valor como argumentador e a validade de suas opiniões, mesmo à custa da harmonia da interação. O estilo centrado no ouvinte preocupa-se mais em estabelecer um clima harmonioso e em atingir um consenso entre os participantes. Cada falante procura adequarse aos demais e apresentar argumentos que contribuam para a formação de uma opinião comum (ou ao menos aceitável) para todos.

Embora KoHNEN não tenha o objetivo de fazer uma análise cultural dos estilos, não pode deixar de observar que os falantes alemães mostravam uma grande tendência a adotar o estilo centrado no falante, no que diferiam dos anglo-saxões. Isto também pode ser visto como conseqüência da escolarização dos alemães, já que há uma grande tradição de debates e de treino da retórica na Alemanha, desde as Disputationen religiosas da Idade Média, e que o treino de discussões e da argumentação faz parte do currículo do ensino médio alemão (cf. Holly et al. 1986).

Estes resultados do estudo de KoHNEN, advindos da análise de discussões institucionalizadas na TV, vêm ao encontro das idéias de BYRNES no que se refere a diferenças nos estilos conversacionais de americanos e alemães em situações informais de comunicação, sendo que falantes alemães utilizariam o estilo centrado no falante, enquanto falantes do inglês parecem priorizar o estilo centrado no ouvinte. 


\section{Estilos conversacionais alemão e brasileiro}

Em minha tese de doutorado (MEIRELEs 1999), investiguei a expressão de dissensão em discussões do alemão em relação às estratégias de trabalho de Face (ou estratégias de polidez deferencial e solidária, retomando a terminologia de BYRNES) e pude observar que a argumentação alemã apresenta-se centrada em argumentos objetivos e utiliza relativamente poucas estratégias de contato com o ouvinte. Tais observações se coadunam com os estudos de SCHRÖDER (2003, 2004) que, embora sob outro enfoque, corroboram a tese da preferência dos alemães por metáforas e argumentos considerados "mais objetivos" em sua argumentação, apelando para a autoridade racional, científica ou tecnológica, enquanto brasileiros preferem referir-se ao seu estado de espírito e ao seu envolvimento pessoal frente às questões em debate.

Mesmo todas as pesquisas existentes ainda estão longe de delinear um "estilo conversacional alemão". Não se pode deixar de ter em mente que o "estilo conversacional" varia muito de acordo com a situação, o tipo de interação, o grau de intimidade entre os participantes e vários outros fatores como sexo, idade etc. Contudo, em situações de debate amigável e argumentação, tudo parece apontar para uma tendência dos alemães para utilizarem argumentos mais “objetivos" em detrimento de argumentos mais ligados à opinião pessoal e aos sentimentos, o que resulta em um estilo conversacional centrado no falante, com poucas estratégias de apelo ao grupo e à relação pessoal dos interlocutores.

Ainda assim há diferenças: em um pequeno estudo posterior, comparando o uso de estratégias de trabalho da Face por falantes alemães e brasileiros de ambos os sexos (Meireles 2001), constatei que mulheres alemãs tendem a utilizar aproximadamente quatro vezes mais expressões de opinião pessoal (eu creio/ acho penso... - ich glaube/finde/denke..., que dão ao interlocutor maior liberdade para discordância e negociação), que os homens alemães. No entanto, o estudo paralelo com diálogos brasileiros mostrou que parece não haver, em português, distinção na freqüência de uso de tais expressões por ambos os sexos. Embora o estudo não seja conclusivo, podemos considerá-lo como uma primeira aproximação do problema, que permite o levantamento de algumas hipóteses.

Primeiramente, tanto em alemão como em português, a freqüência de uso de expressões de opinião pessoal parece aumentar com o grau de 
informalidade da interação. Nos diálogos onde tais expressões são usadas com freqüência há um nível de formalidade e tensão médias e o clima é agradável, semelhante a uma "conversa". Por outro lado, diálogos com um clima tenso e carregado têm pouquíssimas ocorrências destas expressões. Essa busca de consenso e harmonia em discussões é apontada por BROwN \& LEVINSON (1987) como uma característica feminina em diversas culturas nas quais há claras divergências de estilo entre os sexos. Talvez as mulheres alemãs mantenham essa tendência, supervalorizando as expressões de opinião pessoal como um dos meios de integrar o ouvinte em sua argumentação, tendendo assim ao estilo centrado no ouvinte, enquanto os homens alemães se valem principalmente do estilo centrado no falante.

Em segundo lugar, é sabido que brasileiros têm fama de evitar conflitos, o que nos leva a interpretar os resultados obtidos como um indicador de que falantes brasileiros de ambos os sexos dão preferência a esse tipo de comportamento. Assim, poderíamos levantar a hipótese de que, enquanto os homens alemães têm um estilo fortemente centrado no falante (o que corresponde ao observado por BYRNES), as mulheres alemãs tendem a integrar mais freqüentemente elementos de um estilo que leva mais em conta a Face do interlocutor, enquanto brasileiros em geral (homens e mulheres) utilizariam um estilo centrado no ouvinte, à semelhança dos americanos, conforme descrito por BYRNES.

Embora ainda não haja uma quantidade suficiente de estudos que possam fornecer um quadro definido de um estilo conversacional brasileiro em comparação ao alemão (veja p.ex. SIMÕES 1997, SCHRÖDER 2003, 2004), os resultados até o momento apontam para uma maior similaridade com os falantes americanos e uma tendência ao estilo centrado no ouvinte, no qual os participantes estão mais preocupados em manter um clima aparentemente harmonioso e em enfatizar mais os pontos de consenso que os de discordância.

\section{Estilo conversacional e ensino de língua estrangeira}

Em vista do exposto, podemos perceber que, em interações interculturais, o risco de mal-entendidos e de formação de estereótipos, preconceitos e intolerância é muito grande, devido ao desconhecimento da importância das regras do estilo conversacional. Pessoas que participam de tais encon- 
tros freqüentemente passaram por um aprendizado formal da língua estrangeira, que infelizmente ainda é muito voltado à transmissão pura e simples de conteúdos lingüísticos isolados ou apresentados em contextos situacionais extremamente limitados, de caráter quase formulaico.

Embora isso já seja um avanço em relação ao método tradicional de "tradução e gramática”, a dimensão cultural e pragmática ainda é muito pouco explorada. A aula de língua estrangeira deveria alertar os aprendizes para tais fenômenos e procurar aumentar sua sensibilidade para detectar e contornar possíveis dificuldades em interações interculturais. Vale a pena frisar que não se trata de incutir no aprendiz as regras do estilo conversacional da outra cultura, mas apenas alertar para sua existência e de que algumas modificações no próprio estilo certamente serão necessárias para uma interação bem sucedida.

Ao mesmo tempo, como não se pode evitar que julgamentos psicológicos e afetivos sejam gerados pelos choques entre estilos conversacionais diversos, pode-se conseguir que aqueles que interagem em contextos interculturais transformem seus estereótipos negativos como "ah, ele é brasileiro e brasileiros são assim mesmo, superficiais" - em: "ah, ele é brasileiro e brasileiros são assim mesmo, não valorizam tanto a apresentação de dados completos"; ou: "ah, ele é alemão e alemães são assim mesmo, grosseiros" - em: "ah, ele é alemão e alemães são assim mesmo, diretos, mas isso não significa que ele me queira mal". A demolição dos preconceitos não está em negar as diferenças culturais, mas sim em reconhecê-las e respeitá-las como legítimas dentro do contexto particular de cada grupo.

\section{Referências bibliográficas}

Brown, Penelope e Stephen C. Levinson. Politeness. Some universals in language usage. Cambridge, Cambridge Univ. Press 1987.

Byrnes, Heydi. "Interactional style in German and American Conversations". In: Text 6 (2), Amsterdam, de Gruyter 1986, 189-206.

FILIP, Hana. "LIN 108 - Conversation”. University of Rochester Linguistics Department, 1998 http:/ / www.ling.rochester.edu / courses /108 / 108.html - ativa em maio de 2002. 
GÜNTHNER, Susanne. Diskursstrategien in der interkulturellen Kommunikation - Analyse deutsch-chinesischer Gespräche. Tübingen, Niemeyer 1993.

GuMPERZ, John J. e Jenny COOK-GuMPERz. "Introduction: language and the communication of social identity". In: GUMPERz, John J. (ed.): Language and Social Identity, Cambridge, Cambridge Univ. Press 1982, 1-21.

Holdy, Werner, Peter KüHn e Ulrich Putschel. Politische Fernsehdiskussionen Zur medienspezifischen Inszenierung von Propaganda als Diskussion. Tübingen, Niemeyer 1986.

Kohnen, Thomas. Zurückweisungen in Diskussionen. Die Konzeption einer Sprechbandlungstheorie als Basis einer empirisch orientierten Konversationsanalyse. Frankfurt, Peter Lang 1987.

MeIRELES, Selma M. "Dissenskategorien und Face-work-Strategien in deutschen Diskussionen”. In: GLENK, Eva, Eliana FISCHER e Selma MEIRELES (org.): Blickwechsel - XI. ALEG-Kongress - Akten, Band III, São Paulo, Edusp 2005, 276-285.

Meireles, Selma M. "Um estilo feminino de trabalho da Face?” Palestra apresentada na IX Semana da Língua Alemã. Área de Alemão, DLM/ FFLCH-USP, São Paulo 2001.

MEIRELES, Selma M. Estratégias para manutenção de uma boa interação lingüistica Dissensão e trabalho da Face em diálogos do alemão. São Paulo, Humanitas 1999.

MÜLLER-Jaquier, Bernd. “Vorlesung 5 (12.11.1998) - Interaktionsbezogene Diskrimination and Attribution: erste kritische Aspekte der Deutungen von critical incidents". Universität Tübingen. (www.tu-chemnitz.de / phil / ikk / lehrver / ss01 / skripte / ws98_5.html - ativa em maio de 2002).

SCHRÖDER, Ulrike. "Metáforas tecnológicas do cotidiano: uma análise do falar alemão". In: Pandaemonium Germanicum, n.8, São Paulo, Humanitas 2004, 235261.

SCHRÖDER, Ulrike. Brasilianische und deutsche Wirklichkeiten. Eine vergleichende Fallstudie zu kommunikativ erzengten Sinnwelten. Wiesbaden, Deutsche UniversitätsVerlag 2003.

Simões, José S. Marcadores interacionais e modalizadores do português e do alemão falados (Dissertação de mestrado não publicada). São Paulo, FFLCH/ USP 1997. 